\title{
LA RELEVANCIA PRESENTE EN TIEMPO DE PANDEMIA: UN ESTUDIO SOBRE CONSTRUCCIONES VERBALES EN LA ESCRITURA PERIODÍSTICA
}

THE PRESENT RELEVANCE IN PANDEMIC TIMES: A STUDY ON VERBAL CONSTRUCTIONS IN JOURNALISTIC WRITING

\section{A RELEVÂNCIA PRESENTE EM TEMPO DE PANDEMIA: UM ESTUDO SOBRE CONSTRUÇÕES VERBAIS NA ESCRITA JORNALÍSTICA}

\author{
Leandra Cristina de Oliveira | Lattes | leandra.oliveira@ufsc.br \\ Universidad Federal de Santa Catarina
}

\begin{abstract}
María Alejandra Godoy Roa | Lattes| marialejandragodoyr@outlook.com Universidad Federal de Santa Catarina
\end{abstract}

Alison Felipe Gesser | Lattes | felipegesser@gmail.com Universidad Federal de Santa Catarina

Resumen: La noticia es un ambiente oportuno para el estudio de la expresión de anterioridad, especialmente cuando se trata de considerar el dominio de la relevancia presente (RP). En este estudio, la mirada se direcciona a formas variantes en la función de indicar situaciones que denotan el resultado persistente de una situación pasada, un subdominio cubierto por la RP. El interés se deriva de la apreciación de las diferentes formas con las que periódicos hispánicos registran hechos vinculados a la pandemia de la COVID-19, las cuales llaman la atención incluso de hablantes no especialistas en cuestiones del lenguaje. Con el objetivo de analizar esa variación, que aquí se discute a la luz del Funcionalismo Lingüístico/Lingüística centrada en el uso (GIVÓN, 1995; 2001a; 2001b; 2002; HOPPER, 1991; 1998; BYBEE, 2006; 2016) y, por esta razón, evocada a partir de las nociones de dominio funcional y del principio de la estratificación (HOPPER, 1991; GIVÓN, 2002; GÖRSKI; TAVARES, 2017), analizamos el objeto con base en una compilación de cinco noticias de repercusión mundial, en los pasos metodológicos de Oliveira $(2007 ; 2010)$, publicadas en tiempo coincidente en periódicos electrónicos de cuatro países hispánicos (Argentina, Colombia, España y Perú). Los resul- 
tados observados en esta etapa de la investigación señalan: (i) la complejidad implicada en el recorte del subdominio funcional; (ii) la identificación de diferentes capas en el subdominio recortado, como las formas del presente, pretérito perfecto simple, pretérito perfecto compuesto y de locuciones verbales; y (iii) un uso más frecuente del pretérito perfecto compuesto en las muestras de España y de Perú, en las cuales esa forma verbal parece avanzar en el proceso de gramaticalización, de acuerdo con Oliveira (2010).

Palabras clave: Dominiofuncional. Relevancia presente de resultado persistente. Noticias COVID-19. Corpus electrónico.

Abstract: The news is a convenient environment for the study of the expression of anteriority, especially when taking into consideration the domain of present relevance (PR). This study aims to investigate different variant forms functioning as indicators to situations that denote the ongoing result of a past situation, a subdomain that is contained by the PR domain. Our interest stems from the appreciation of different ways in which Hispanic newspapers report facts related to the COVID-19 pandemic, which can even catch the eye of speakers who are not language experts. In order to analyze this variation phenomenon, discussed here in light of the Linguistic Functionalism or Use-centered Linguistics (GIVÓN, 1995; 2001a; 2001b; 2002; HOPPER, 1991; 1998; BYBEE, 2006; 2016) and, for that reason, evoked from the notions of functional domain and layering principle (HOPPER, 1991; GIVÓN, 2002; GÖRSKI; TAVARES, 2017), we scrutinized our object based on a compilation of five internationally significant facts that were published simultaneously in online newspapers from four Hispanic countries (Argentina, Colombia, Spain and Peru) under the methodological steps of Oliveira (2007; 2010). The results observed at this stage of the research suggest: (i) the complexity of isolating the functional subdomain; (ii) the identification of different layers within the isolated subdomain, such as present forms and the past forms pretérito perfecto simple, pretérito perfecto compuesto in addition to circumlocutory phrases; and (iii) a more frequent use of the pretérito perfecto compuesto tense in the samples of Spain and Peru, in which this verbal form seems to advance in the grammaticalization process, according to Oliveira (2010).

Keywords: Functional domain. Present relevance of ongoing results. COVID-19 news. Electronic corpus. 
Resumo: A notícia é um ambiente oportuno para o estudo da expressão de anterioridade, especialmente quando em consideração o domínio da relevância presente (RP). Neste estudo, o olhar se direciona a formas variantes na função de indicar situações que denotam o resultado persistente de uma situação passada, um subdomínio recoberto pela RP. O interesse decorre da apreciação das distintas formas com que jornais hispânicos noticiam fatos vinculados à pandemia da COVID-19, as quais chamam a atenção, inclusive, de falantes não especialistas em questões da linguagem. Com o objetivo de analisar essa variação, aqui discutida à luz do Funcionalismo Linguístico/Linguística centrada no uso (GIVÓN, 1995; 2001a; 2001b; 2002; HOPPER, 1991; 1998; BYBEE, 2006; 2016) e, por essa razão, evocada a partir das noções de domínio funcional e do princípio da estratificação (HOPPER, 1991; GIVÓN, 2002; GÖRSKI; TAVARES, 2017), analisamos o objeto com base em uma compilação de cinco notícias de repercussão mundial, nos passos metodológicos de Oliveira $(2007 ; 2010)$, publicadas em tempo coincidente em jornais eletrônicos de quatro países hispânicos (Argentina, Colômbia, Espanha e Peru). Os resultados observados nesta etapa da pesquisa sinalizam para: (i) a complexidade implicada no recorte do subdomínio funcional; (ii) a identificação de diferentes camadas no subdomínio recortado, como as formas de presente, de pretérito perfeito simples, pretérito perfeito composto e de locuções verbais; e (iii) um uso mais frequente do pretérito perfeito composto nas amostras da Espanha e do Peru, nas quais essa forma verbal parece avançar no processo de gramaticalização, conforme Oliveira (2010).

Palavras-chave: Domínio funcional. Relevância presente de resultado persistente. Notícias COVID-19. Corpus eletrônico.

\section{Introducción}

El año de 2020 sin duda estará marcado en la historia mundial por la desestabilización social provocada por la pandemia de la COVID-19, decretada el 11 de marzo de ese mismo año por la Organización Mundial de la Salud (OMS). La fecha hace despertar las diferentes sociedades del planeta, enfocadas en la expansión del virus por el mundo, sus consecuencias, el avance de la ciencia y diversos otros sucesos que estampan la continuidad y el resultado de una situación iniciada en un punto pasado - en este caso específico, que antecede en algunos meses el 11 de marzo de 2020. En el drama de este escenario, como investigadores de las categorías Tiempo y Aspecto hemos permanecido atentos a la 
codificación de la función de la relevancia presente en las noticias vehiculadas por periódicos hispánicos, que es el tema de este estudio.

Tal y como detallamos en el debate teórico más adelante, la relevancia presente es un dominio funcional que recubre las nociones experiencial, resultativa y actualidad de la situación (OLIVEIRA, 2010), que pueden concretizarse a través del empleo de distintas construcciones lingüísticas ${ }^{1}$, como el pretérito perfecto compuesto, las construcciones perifrásticas, los complementos adverbiales, entre otros. Cabe aclarar que en esta discusión nos referimos específicamente al español, lengua en que nos hemos centrado en las últimas investigaciones (OLIVEIRA, 2007; 2010; 2011; OLIVEIRA; GESSER, 2014; 2015; OLIVEIRA; GODOY ROA, 2020; GESSER, 2015; 2018; GODOY ROA, 2017). En el estudio de este dominio funcional, aquí comprendido como un área en la gramática que abarca diferentes estratos (HOPPER, 1991; GÖRSKI et al., 2003; GÖRSKI; TAVARES, 2017; GÖRSKI, 2020), es imprescindible la consideración de dos categorías íntimamente relacionadas - el Tiempo y el Aspecto, que se discuten en el apartado dedicado a los debates teóricos situados en una perspectiva funcionalista (CASTILHO, 2003; 2010; COMRIE, 1981; 1985; GIVÓN, 2001; GARCÍA FERNÁNDEZ, 2000; FOSSILE, 2012; BYBEE, 2016), recuperando además los aportes de carácter filosófico sobre la categoría verbal (BELLO, 1979 [1810]; REICHENBACH, 1960).

El objetivo central de la investigación es identificar las construcciones capaces de codificar el resultado persistente de una situación pasada - una subfunción de la relevancia presente - en noticias publicadas en los periódicos electrónicos de cuatro países hispanohablantes: Argentina, Colombia, España y Perú. Para ello, se considera como criterio metodológico la semana del 9 al 17 de marzo de 2020 y se contemplan cinco noticias que tuvieron un gran impacto en los medios internacionales: el lunes negro en las bolsas del mundo, la suspensión de vuelos desde Italia a España, el anuncio de la pandemia por parte de la OMS, el anuncio del gobierno chino sobre la superación del pico de contagio y el resultado de la prueba de COVID-19 del presidente Trump. En diálogo con los resultados de Oliveira (2010), quien describe la multifuncionalidad del pretérito perfecto compuesto en una muestra de naturaleza semejante, planteamos el siguiente cuestionamiento: si en algunas de las variedades hispanoamericanas la presencia del pretérito perfecto compuesto - for-

\footnotetext{
${ }^{1}$ Se asume el concepto de construcción a partir de Bybee $(2006 ; 2016)$, autora que concibe la gramática como un continuo de construcciones que representan la organización cognitiva de experiencias con la lengua. La construcción constituye la forma más adecuada para la representación de la gramática, ya que esta se organiza en construcciones que son secuencias morfológicas y/o sintácticas convencionalizadas, parcialmente esquemáticas, y que responden a una representación semántica determinada. En otras palabras, se trata de formas gramaticales (que van desde un morfema hasta una locución) que existen para expresar una determinada función o significado en la lengua.
} 
ma que según la literatura desempeña, entre diferentes funciones, el valor de la relevancia presente (OLIVEIRA, 2010) - no es expresiva, ¿a qué construcciones recurren los periodistas cuando quieren referirse al resultado persistente de una situación ${ }^{2}$ pasada? Buscaremos contestar a este cuestionamiento a partir de la consideración de los debates teóricos mencionados líneas arriba y a los cuales dedicamos la sección que sigue.

\section{El objeto de estudio a la luz del Funcionalismo/Lingüística centrada en el uso}

\subsection{Situando el campo}

El reconocimiento de la naturaleza dinámica y mutable de las lenguas es una orientación elemental en la Lingüística. Basta con que consideremos ya en Saussure la dicotomía sincronía y diacronía, que concilia la posibilidad de una descripción de la regularidad de un estado de la lengua en un dado momento y el reconocimiento del cambio en el pasaje de un estado a otro.

La consideración del cambio lingüístico en la descripción de las lenguas, aunque ajena a las preocupaciones del estructuralismo saussureano, aparece en estudios anteriores y posteriores a ese autor. En lo que concierne a trabajos realizados después de Saussure, destacamos las perspectivas interesadas en la variación y cambio y en la funcionalidad de los fenómenos en el uso, como la Teoría de la variación y cambio (LABOV, 2008 [1972]; WEINREICH; LABOV; HERZOG, 2006 [1968]) y de la Lingüística centrada en el uso, o Funcionalismo Lingüístico de perspectiva norteamericana (GIVÓN, 1995; 2001a; 2001b; 2002) HOPPER, 1991; BYBEE, 2006; 2016).

Fundamentados en este último campo, pero recuperando concepciones del primero cuando sea conveniente, asumimos en este estudio la lengua como actividad siempre en movimiento y en constante adaptación, a partir de la cual (i) nuevas formas están siempre emergiendo en la codificación de funciones ya existentes y (ii) nuevas funciones surgen en formas antiguas (HOPPER, 1991). Desde esa perspectiva, la gramática y el discurso son realidades indisociables - la gramática está al servicio de la comunicación y es moldeada a partir del discurso (GIVÓN, 1995) y el significado vinculado a la forma es siempre inestable.

En el estudio de la expresión de pasado, Oliveira (2010), Oliveira y Gesser (2015) y Gesser (2018) se han fundamentado en la perspectiva funcionalista en el debate sobre la variación de formas verbales como el pretérito perfecto simple y el pretérito perfecto compuesto (de aquí en adelante, PPS y PPC, respectivamente) y la multifuncionalidad de esta última forma en la lengua castellana. Entre los debates funcionalistas centrales 
que emergen en y a partir de esas investigaciones, se encuentran: (i) la descripción del proceso de gramaticalización del perfecto compuesto a partir de la aplicación de los cinco principios de Hopper (estratificación, divergencia, especialización, persistencia y descategorización); (ii) la discusión sobre la variación entre las formas PPS y PPC, que aquí se consideran como estratos que compiten en el macrodominio de la anterioridad; (iii) las etapas de la gramaticalización del PPC en que se encuentran algunas variedades hispanohablantes; y (iv) la constatación de diferencias en el uso del PPC entre los países, sobre todo entre España y regiones de Hispanoamérica, a partir de muestras de lengua escrita y de traducción audiovisual, así como la consideración de la percepción de los usuarios en cuestionarios sobre el empleo y los valores del pretérito perfecto compuesto.

En este recorrido con miradas hacia el mismo objeto, pero con propósitos distintos, participan autores brasileños con sólida trayectoria investigativa sobre fenómenos del portugués de Brasil a la luz del Funcionalismo Lingüístico/Lingüística centrada en el uso y de la Teoría de la gramaticalización, entre los cuales destacamos a Edair Görski, docente e investigadora del Programa de Posgrado en Lingüística de la Universidad Federal de Santa Catarina (UFSC), con doctorado en Lingüística de la Universidad Federal de Río de Janeiro (UFRJ), cuya tesis ha sido dirigida por Sebastião Josué Votre, uno de los precursores del Funcionalismo en Brasil y gran actuante en proyectos de este campo (GÖRSKI; OLIVEIRA; PIMPÃO, 2020). Destacar a Edair Görski en este estudio es una manera de retribuir los valiosos aportes que nos ha brindado en los cursos impartidos, en su lectura atenta de nuestros trabajos en el proceso de la maestría al doctorado, en los eventos, en las mesas de debate y en las conversaciones informales. El diálogo que se establece con Görski en este estudio se vincula a lo que consideramos una de sus grandes contribuciones al campo de la Lingüística - la descripción de fenómenos lingüísticos desde la perspectiva sociofuncionalista (GÖRSKI, 2008; 2020; GÖRSKI et al., 2003; GÖRSKI; TAVARES, 2013; 2017), la cual vincula la Teoría de la variación y cambio (TVC) y el Funcionalismo norteamericano (o Lingüística centrada en el uso, como nominación más reciente y que en este texto acogemos).

No disponemos de espacio suficiente para pormenorizar la perspectiva sociofuncionalista y los puntos de confluencia y divergencia entre las teorías que el modelo abarca. Teniendo en cuenta los propósitos de la presente investigación, nos restringiremos al debate sobre la demarcación de la variable lingüística, al que conviene vincular las nociones de dominio funcional y estratificación (layering).

Desde la perspectiva de la gramática emergente, se reconocía en párrafos anteriores 
la posibilidad del surgimiento de nuevas formas para antiguas funciones y nuevas funciones para viejas formas. En un dominio funcional, es posible constatar diferentes formas que compiten por el mismo trabajo lingüístico - en los términos de Poplack (2011) -, lo que aquí asumimos como formas que desempeñan la misma función comunicativa, en los pasos de Givón (2002) y Görski (2020). En la otra dirección, es común que en su proceso de cambio una misma forma se extienda a otros dominios y pase a desempeñar nuevas funciones.

En lo que concierne al objeto de estudio al que nos dedicamos, tal y como discutimos en este texto, se verifican ambas situaciones: (i) la emergencia de una construcción perifrástica latina que pasaría a funcionar en el dominio de la expresión resultativa; y (ii) el paso de esta construcción a tiempo verbal compuesto, el cual, a través de un proceso gradual de gramaticalización, pasaría a competir con otras formas en los diferentes dominios cubiertos por el macrodominio de la anterioridad.

A esa perspectiva que evoca el dinamismo de las formas lingüísticas se vincula la noción de estratificación (layering), uno de los cinco principios establecidos por Hopper (1991) para averiguar un proceso de gramaticalización en curso. Según Hopper (1991, p. 22), la estratificación implica que en un dominio funcional amplio surjan nuevos estratos (layers) que pasan a coexistir con los antiguos. Dicho fenómeno sucede dada la realidad de que el surgimiento de nuevas formas funcionales no hace desaparecer las formas anteriores que ocupaban el mismo dominio.

En los estudios llevados a cabo por Edair Görski y colaboradoras, se encuentran debates proficuos sobre la relación entre las nociones de dominio funcional y estratificación (del Funcionalismo) y las nociones de variable lingüística y variación (de la Sociolingüística laboviana). Considerando los límites de espacio que se nos imponen, recuperamos la publicación Görski y Tavares (2017) debido a la amplia discusión sobre esa interfaz, que comprende los puntos confluentes sin ignorar las divergencias, pero especialmente por la semejanza entre nuestro objeto y el que usan las autoras para ejemplificar los postulados que presentan.

Görski y Tavares (2017) proponen una discusión minuciosa sobre la interfaz variación-gramaticalización - asumida desde una mirada funcionalista - respaldada en el pionerismo de las lingüistas canadienses Shanna Poplack y Sali Tagliamonte respecto a ese debate. El eje central del capítulo es el tema de la compleja tarea de recortar el objeto de investigación a la luz de la interfaz propuesta, tema de especial pertinencia para el presente estudio particularmente por la aproximación entre el objeto ilustrado por las 
investigadoras y el objeto que aquí se considera, ambos vinculados a la categoría verbal.

La noción de dominio funcional ocupa lugar de destaque en Görski y Tavares (2017), puesto que en el análisis de la variación-gramaticalización del macrodominio TAM (Tiempo, Aspecto y Modalidad, de acuerdo con Givón (2001a)) uno de los primeros compromisos del investigador es recortar el dominio a ser considerado. Desde la perspectiva de la tipología funcional, se considera que las lenguas pueden codificar el mismo dominio funcional a través de más de un medio estructural y esos diferentes tipos de estructura se agrupan como miembros de meta-tipos (meta-types) más generales (GIVÓN, 2002, p. 22). Así, en la tipología gramatical "se enumeran los principales medios estructurales por los cuales diferentes lenguas - y ocasionalmente una misma lengua - codifican el mismo dominio funcional” - Givón (2002, p. 213, traducción nuestra ${ }^{3}$ ), también citado por Görski y Tavares (2017, p. 43). Aunque se pueda asumir los dominios funcionales como universalmente tipificados, la noción es relativa y no absoluta:

[...] frecuentemente un dominio grande se subdivide en subdominios que se entrecruzan e interactúan; además, los dominios funcionales más grandes también pueden superponerse parcialmente. En este sentido, el dominio funcional puede verse como superordenado y recubrir áreas funcionales generales (macrodominios) o más restringidas (subdominios o microdominios), dependiendo del ajuste de foco del lente del analista. Así, lo que es un dominio en una determinada perspectiva puede ampliarse y verse como macrodominio, o restringirse y verse como microdominio, en otras perspectivas $^{4}$ (GÖRSKI; TAVARES, 2017, p. 46, lo destacado es nuestro).

Referente al punto que destacamos en la cita anterior, coincidimos con las autoras al reconocer la conveniencia de recuperar la metáfora del lente para ilustrar el carácter relativo del dominio funcional: "el ajuste de foco es lo que va a determinar el alcance y los posibles límites del dominio en consideración"5 (GÖRSKI; TAVARES, 2017, p. 49). El ejemplo del dominio funcional complejo TAM nos será útil en el recorte de nuestro dominio funcional. Según Görski y Tavares (2017), (i) si se amplía el foco del lente, se alcanza un dominio en que se articulan tres categorías (Tiempo, Aspecto y Modalidad) y (ii) si se ajusta el foco sobre cada una de ellas, pasamos a observar tres dominios distintos. Desde ahí,

Se opera con la idea de un fenómeno superordenado, cuyos límites no siempre son claros y cuyo alcance funcional es gradiente: macrofunción $>$ funciones $>$ subfunciones $[\ldots]$, una noción que puede extenderse 
a: macrodominio $>$ dominio $>$ microdominio funcional ${ }^{6}$ (GÖRSKI; TAVARES, 2017, p. 49).

Frente a lo expuesto, las autoras tratan el dominio funcional recortado, la futuridad, a partir de Gibbon (2014) como "un dominio complejo que abarca otros dominios igualmente complejos, los cuales comparten rasgos de aspecto, modalidad y tiempo"7 (GÖRSKI; TAVARES, 2017, p. 55-56). Los subdominios bajo el ámbito de este dominio son la referencia futura/tiempo, la habitualidad/aspecto y el acto de habla manipulativo/ modalidad.

Como hemos mencionado a partir de Hopper (1991) y Givón (2002), diferentes estructuras pueden codificar un mismo dominio funcional, lo que implica asumir que en el dominio de la futuridad pueden emerger y funcionar diferentes estratos, como el futuro perifrástico, el futuro sintético y el presente, por citar algunos. Una cuestión para plantearse es si esas formas, en el dominio específico, preservan el mismo significado, lo que nos lleva a adentrarnos en el debate sobre la posibilidad de establecerse la equivalencia semántica en los niveles más allá de la fonología - clásica polémica entre Lavandera (1978) y Labov (1978) en el seno de la Sociolingüística, que Oliveira (2009) recobra al tratar de la noción de anterioridad en algunas variedades castellanas.

En el ámbito de los estudios sobre la variación de fenómenos morfosintácticos, sintácticos y semánticos, la noción de "mismo significado" para diferentes formas variantes, que aparece en la consideración de la variable lingüística, se actualiza y pasa a interpretarse en el nivel de la comparabilidad funcional (LAVANDERA, 1978) o como formas que expresan la misma función comunicativa, según Milroy y Gordon (2003), citados por Görski y Tavares (2017, p. 37).

En el debate sobre las contribuciones mutuas entre variación y gramaticalización para la descripción de un fenómeno variable, las lingüistas brasileñas, fundamentadas en Tagliamonte (2006), sostienen que "a medida que los análisis variacionistas van alcanzando niveles gramaticales más altos, la correlación forma-significado referencial se va desplazando a forma-función discursiva"8 (GÖRSKI; TAVARES, 2017, p.37). Desde ese punto, pasan a discutir el diálogo productivo entre los dos campos sin desconsiderar los puntos de convergencia y de divergencia, sobre los cuales no nos detenemos en este texto.

En el seno de la Sociolingüística, una variación lingüística señala la existencia de dos o más formas distintas - las formas variantes - que expresan el mismo significado en un dado periodo y en una determinada comunidad de habla. Las variantes actúan en una variable, es decir, en un lugar de la gramática que al analista le interesa investigar. 
Tomando el mismo ejemplo de las autoras, la futuridad sería la variable y las variantes que funcionan en este espacio/función podrían ser el futuro sintético, el futuro perifrástico y el presente, por ejemplo. Si tomamos en cuenta nuestro objeto, la anterioridad sería la variable y sus formas variantes podrían ser el perfecto simple, el perfecto compuesto y otras formas dependiendo del contexto (OLIVEIRA, 2009). A partir del análisis estadístico multivariado, a la sociolingüística le cabría describir los factores lingüísticos y extralingüísticos que condicionan la variación (LABOV, 2008 [1972]).

Si por un lado la metodología de la Sociolingüística contribuye, entre otros factores, a la descripción de un fenómeno variable a partir de la consideración de factores internos y externos, por otro "la gramaticalización ayuda a contestar a la pregunta sobre cómo y cuándo surgió cada forma variante que compone una determinada variable lingüística" ${ }^{\prime}$ (GÖRSKI; TAVARES, 2017, p. 38), es decir, puede recubrir el punto de emergencia de una determinada forma y su trayectoria de cambio morfosintáctico y semántico. Además, el estudio fundamentado en la perspectiva de la gramaticalización puede obtener hipótesis de orden diacrónico a las que el analista puede recurrir (y realizar pruebas) para la explicación de patrones sincrónicos (GÖRSKI; TAVARES, 2017, p. 39).

Otro debate conveniente que proponen las autoras y que es bastante útil para los propósitos del presente estudio, tal y como se busca demostrar en la sección 2.3 , se refiere a la circunscripción de la variable lingüística o del dominio funcional en las perspectivas de la Sociolingüística y del Funcionalismo, respectivamente. A partir de nuestro objeto de estudio y recuperando caminos recorridos anteriormente (OLIVEIRA, 2007; 2009; 2010), ilustraremos las dos perspectivas discutidas por las autoras: la perspectiva de variación estricta y la perspectiva del proceso de gramaticalización. Antes contextualizaremos el objeto de investigación desde el punto de partida de las categorías Tiempo y Aspecto - sección 2.2.

\subsection{El continuo de la relevancia presente: entre el Tiempo y el Aspecto}

Tal y como mencionado en la introducción del presente texto, en este estudio se adentra en el análisis de datos contemplados en el género noticia con una mirada hacia el subdominio de la relevancia presente de resultado persistente, teniendo en cuenta la concepción del Tiempo y el Aspecto como categorías cognitivo-funcionales que pertenecen al complejo dominio funcional TAM (GIVÓN, 2001, p. 285).

El Tiempo, según Comrie (1985, p. 2), puede representarse como una línea recta, en la que el pasado se representa de forma convencional a la izquierda y el futuro a la de-

\footnotetext{
${ }^{9}$ [...] a gramaticalização auxilia a responder a questão de como e quando surgiu cada forma variante componente de dada variável linguística.
} 
recha; en esta línea recta, el presente se localizaría en el centro y como punto cero. En esta misma dirección, autores como Givón (2001, p. 153) afirman que en la comunicación natural los hablantes presuponen que sus interlocutores mantienen un modelo mental de la situación de habla en el que se encuentra el tiempo de habla, caracterizado como la referencia temporal default, o sea, una referencia no marcada a partir de la cual se establecen los tiempos absolutos.

Basado en Reichenbach (1960), García Fernández (2000, p. 22) afirma que se trata de una relación establecida entre dos momentos: el punto de la línea temporal en que se sitúa el evento y el momento de la enunciación. Esta relación puede darse de forma simultánea o sucesiva, incluyendo relaciones de anterioridad y colocando en la línea tres combinaciones posibles entre los puntos:

Figura 1 -Temporalidad de las formas absolutas

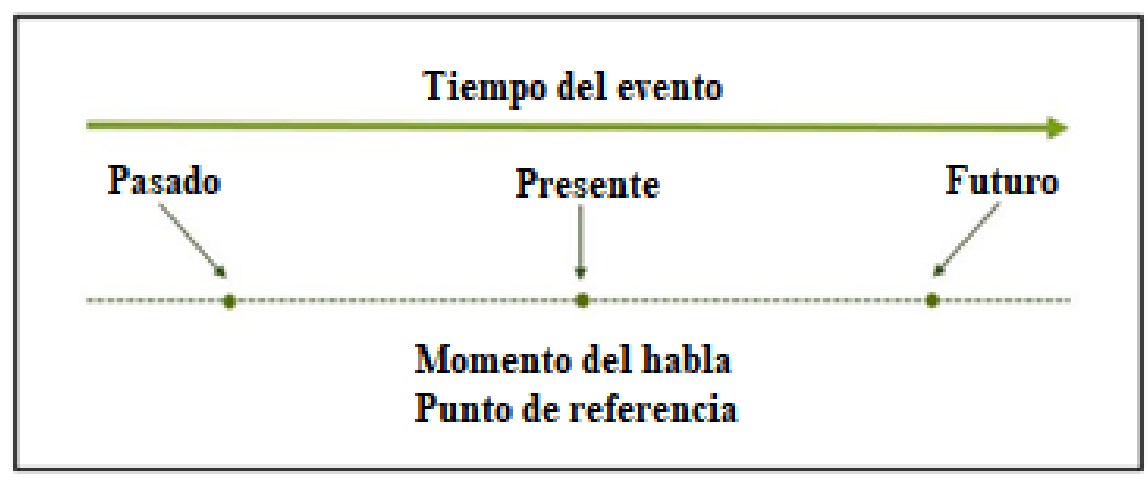

Fuente: Adaptado de Givón (2001, p. 286).

A partir de la línea temporal vemos que los tiempos verbales que se configuran son pasado, futuro y presente. El primero se caracteriza por ser un evento que precede el tiempo del habla; el segundo es un evento posterior al tiempo del habla; y el tercero es un evento simultáneo al tiempo del habla. Sin embargo, las relaciones temporales que se establecen al observar varias conjugaciones de tiempos verbales dejan en evidencia que existen más de tres elementos en juego, razón por la cual autores como Reichenbach (1960), Bello (1979 [1810]), Comrie (1981; 1985), García Fernández (2000), entre otros, caracterizan los eventos principales y sus relaciones a partir de tres elementos: el momento de la enunciación ( $\mathrm{S}$-point of speach); el punto del evento denotado por el predicado ( $\mathrm{E}$ - point of the event); y el punto de referencia relevante para la localización del evento ( $\mathrm{R}$ - point of reference). 
Estos puntos son, según Reichenbach (1960), necesarios para codificar el significado de cualquier forma verbal flexionada, además de establecer relaciones que se dan a partir de la expresión de la relación entre más puntos de los que están en la línea temporal. El cuadro a continuación presenta de manera resumida las estructuras temporales en la lengua española:

Cuadro 1 - El sistema verbal

\begin{tabular}{|c|c|c|c|}
\hline Estructura & Denominación $^{10}$ & $\begin{array}{l}\text { Nombre tradi- } \\
\text { cional }\end{array}$ & Ejemplo \\
\hline$E-R-S$ & Antepretérito & $\begin{array}{l}\text { Pretérito plus- } \\
\text { cuamperfecto }\end{array}$ & $\begin{array}{l}\text { Carlos nos contó que } \\
\text { Juan había llegado a las } \\
\text { tres. }\end{array}$ \\
\hline$E, R-S$ & Pretérito & $\begin{array}{l}\text { Pretérito perfec- } \\
\text { to simple / preté- } \\
\text { rito imperfecto }\end{array}$ & $\begin{array}{l}\text { Mi hermano llegó ayer. } \\
\text { Ayer estaba en Madrid. }\end{array}$ \\
\hline $\begin{array}{l}R-E-S \\
R-S, E \\
R-S-E\end{array}$ & Pospretérito & Condicional & $\begin{array}{l}\text { La prensa anunció el día } \\
\text { quince que el presidente } \\
\text { dimitiría ayer. }\end{array}$ \\
\hline$E-S, R$ & Antepresente & $\begin{array}{l}\text { Pretérito perfec- } \\
\text { to compuesto }\end{array}$ & $\begin{array}{c}\text { El director ha llamado } \\
\text { esta mañana. }\end{array}$ \\
\hline$S, R, E$ & Presente & Presente & Estudio Derecho. \\
\hline$S, R-E$ & Pospresente & - & $\begin{array}{c}\text { Vamos a comprarlo pron- } \\
\text { to. }\end{array}$ \\
\hline $\begin{array}{l}S-E-R \\
S, E-R \\
E-S-R\end{array}$ & Antefuturo & Futuro perfecto & $\begin{array}{l}\text { Los actores llegarán a las } \\
\text { ocho, pero el público hab- } \\
\text { rá entrado en la sala media } \\
\text { hora antes. }\end{array}$ \\
\hline$S-R, E$ & Futuro & Futuro & $\begin{array}{c}\text { Lo compraremos la sema- } \\
\text { na que viene. }\end{array}$ \\
\hline$S-R-E$ & Posfuturo & - & - \\
\hline
\end{tabular}

Fuente: Adaptado de García Fernández (2000, p. 25-26).

El cuadro ilustra las estructuras temporales representadas por la relación entre E, $S$ y R a partir de símbolos como la coma que expresa simultaneidad y el guion que expresa anterioridad del elemento a la izquierda. Nos atendremos aquí a la explicación de la relación establecida por la fórmula $\mathrm{E}-\mathrm{S}, \mathrm{R}$, a partir de la cual se interpreta el subdominio que nos interesa: un evento pasado (E) que es anterior a dos puntos coincidentes en el punto cero: el momento del habla $(S)$ y el momento de la referencia $(\mathrm{R})$.

La estructura E - S,R codifica la expresión del denominado antepresente (BELLO,

${ }^{10}$ Nomenclatura establecida por Bello en su Análisis ideológico de los tiempos de la conjugación castellana (1972 $[1841])$. 
1979 [1810]), expresando un pasado que se vincula al momento de la enunciación, ya que el punto de referencia es simultáneo y no anterior al punto de la enunciación. Así, estamos frente a una relación que establece que el punto del evento es un punto anterior a la relación de simultaneidad entre la enunciación y la referencia. En la lengua castellana podemos encontrar diferentes formas disponibles para servir a esta función, como es el caso del tiempo verbal pretérito perfecto compuesto.

Estas relaciones temporales no pueden separarse de las nociones semánticas que se dan a nivel cognitivo cuando codificamos los eventos, ya que, como afirma Bybee (2016),

[...] está claro que, como seres humanos, no experimentamos el tiempo de una manera directamente lineal, tampoco estamos inclinados a hablar de él así. Por el contrario, la mezcla de tiempos y aspectos que evolucionaron a la expresión gramatical en las lenguas del mundo hizo reflejar la experiencia humana de situaciones y sus aspectos temporales, y esta experiencia no es uniforme ni simétrica a través del dominio tiempo ${ }^{11}$ (BYBEE, 2016, p.295).

En esta perspectiva, autores como Comrie (1981), Castilho (2003; 2010) y Fossile (2012) también afirman que la expresión de la temporalidad en lenguas como el español no puede estudiarse de forma alejada de la noción de Aspecto, puesto que entre esta categoría y la categoría Tiempo existe un continuo que va desde la expresión del tiempo externo hasta la expresión del tiempo interno de un evento.

El aspecto verbal sería la relación entre el tiempo de la situación (tiempo en el que se desarrolla el evento denotado) y el tiempo del foco (periodo durante el cual es válida una determinada afirmación en un momento dado). Esta última relación establece dos valores semánticos principales para referirnos al Aspecto: imperfectivo y perfectivo. El primero hace referencia a eventos no acabados y el segundo a eventos acabados. Estos dos tipos de contenidos semánticos pueden referirse a eventos habituales, continuos, iterativos, inceptivos o progresivos (imperfectivos) o a eventos puntuales o acabados (perfectivos).

Es frecuente considerar el sentido de la temporalidad (presente, pasado y futuro) como información gramatical primaria de las formas verbales. Sin embargo, en la base latina el primer sentido era el aspectual (infectum/no acabado y perfectum/acabado). En los términos de Ilari (2001, p. 102), citado por Oliveira (2010), el sentido exacto de vixit

\footnotetext{
${ }^{11}$ [...] está claro que, como seres humanos, não experienciamos o tempo de um modo diretamente linear, nem estamos inclinados a falar sobre ele dessa maneira. Ao contrário, a mistura de tempos e aspectos que evoluíram para expressão gramatical nas línguas do mundo veio a refletir a experiência humana de situações e seus aspectos temporais, e essa experiência não é uniforme nem simétrica através do domínio de tempo.
} 
(vivió) indica que el individuo había completado la acción de vivir - él vivió hasta el final (por lo tanto, murió). En otras palabras, no se presentaba la situación como pasada, sino como cumplida en el momento del habla. Esta oposición entre dos sistemas (cumplido/ no cumplido) se pierde ya en el latín vulgar, en el que la semántica de la situación expresa por las formas verbales pasa a orientarse por el sentido temporal (anterioridad, simultaneidad y posterioridad).

Pese a dicho cambio en la interpretación primaria de la categoría verbal, las lenguas latinas como el español preservan en su morfología tanto la información temporal como aspectual, aunque el contexto más amplio puede influir en estas lecturas.

En referencia al aspecto que aquí nos interesa, el que demarca la relevancia presente, en el latín clásico el perfecto amauisti encierra dos valores: el de presente perfecto, que señala una situación vinculada o relevante al presente; y el de pretérito, que vincula la situación a un periodo pasado sin relevancia presente. En la evolución del latín clásico al latín vulgar, el valor que parece predominar es el que heredan las lenguas románicas - el valor de pretérito (HARRIS, 1982; OLIVEIRA, 2010). Desde ahí, surge en el latín vulgar la construcción epistulam scriptam habeo indicando el aspecto Permansivo que desaparecía del Perfectum latino. Así, pasa a emplearse la construcción habere + objeto modificado + participio flexionado en la expresión de estados presentes resultantes del pasado (CÂMARA JÚNIOR, 1970; HARRIS, 1982; SAID ALI, 1964; SQUARTINI; BERTINETTO, 2000).

\subsection{El lente sobre el objeto}

Como se sugiere en algunas partes del presente texto, el análisis de fenómenos lingüísticos en el nivel morfosintáctico nos impone algunos retos, como: (i) recortar el dominio funcional del cual participan los estratos/formas variantes; (ii) reconocer la correspondencia funcional de los estratos considerados; (iii) delimitar una función en el continuo de significaciones de una forma; y (iv) alcanzar el punto inicial y las motivaciones para el proceso de cambio y variación en el sistema lingüístico. Todos estos desafíos están presentes en la investigación que aquí se expone y nos han acompañado en trayectorias anteriores.

A través de la investigación basada en un corpus de noticias electrónicas, fundamentada en postulados dialectológicos, Oliveira (2007) y Oliveira (2013) analizan la variación entre las formas simple y compuesta del pretérito perfecto castellano con el objetivo de verificar la frecuencia de uso de esas formas verbales en periódicos virtuales de siete países hispánicos: Argentina, Bolivia, Chile, Cuba, España, México y Perú. A partir 
del control de los factores lingüísticos - tipo verbal, número de los complementos (singular o plural) y contexto temporal (codificado a partir de marcadores explícitos e implícitos) - y de los criterios metodológicos para la construcción del corpus - coincidencia temática y temporal del suceso noticiado y de su publicación -, los estudios dialogan con las nociones de lengua y norma de la lingüística coseriana (COSERIU, 1952; 1973; 1977; 1982). En los referidos estudios se verifica una presencia expresiva del pretérito perfecto simple en contextos de pasado (pre-hodierno) y de antepresente (hodierno) en todas las variedades, con el aumento significativo del perfecto compuesto en la variedad peninsular. Aunque se evoque a menudo el contexto presente codificado por marcadores como hoy, esta mañana, este mes, el presente siglo etc. como ambiente favorable al empleo del PPC ${ }^{12}$, en los resultados de Oliveira (2007) esta forma verbal no aparece con frecuencia expresiva sobre todo en las variedades hispanoamericanas: PPS /95,5\% y PPC/4,5\% (periódico de Argentina); PPS/71,4\% y PPC/28,6\% (periódico de Bolivia); PPS/85,7\% y PPC/14,3\% (periódico de Chile); PPS/95,7\% y PPC/4,3\% (periódico de Cuba); PPS/67,7\% y PPC/32,3\% (periódico de España); PPS/100\% y PPC/0\% (periódico de México); y PPS/81\% y PPC/19\% (periódico de Perú). En consonancia con autores como Lapesa (1981), se testifica en Oliveira (2007, p. 121) que en Latinoamérica el PPC parecía reemplazarse por el PPS. Desde ahí, podríamos considerar que las variedades hispanoamericanas avanzan en el proceso de cambio de las formas de la anterioridad de modo más acelerada que la variedad peninsular. Pero, como se hace camino al andar, la lectura diacrónica y la secuencia de la investigación nos llevaron a nuevas respuestas y a otros interrogantes ${ }^{13}$, en los que de manera más o menos directa estuvieron presentes los desafíos que se mencionan al inicio de esta sección.

Frente al reconocimiento de que el recorte dialectológico no era suficiente para la comprensión del distinto comportamiento entre las variedades y entre las formas verbales consideradas, Oliveira (2010) pasa de la perspectiva más estricta de la variación a la perspectiva del proceso de gramaticalización - en los términos de Görski y Tavares (2017). Con el propósito de comprender mejor el objeto, la investigación se direcciona a lo que parece dar impulso a la variación en la anterioridad: el proceso lento y gradual de gramaticalización a partir del cual emerge el pretérito perfecto compuesto - quizás hoy una de las formas prototípicas en el dominio de la relevancia presente.

\footnotetext{
${ }^{12}$ En Oliveira (2007) y Alarcos Llorach (1984) pueden encontrarse diversas referencias que tratan de justificar la diferencia de uso entre el PPS y el PPC a partir de la presencia de modificadores temporal ayer, la semana pasada>canté; hoy, esta semana> he cantado.

${ }^{13}$ Nos referimos a los estudios sobre los límites para la consideración de las formas del PPS y del PPC como formas variantes (OLIVEIRA, 2009) y la actuación de la modalidad epistémica en el uso de esas formas verbales (OLIVEIRA, 2008; GESSER, 2015; 2018), a los cuales el lector interesado podrá acceder.
} 
En la literatura, se describen diferentes cambios sintácticos y semánticos por los que pasa la perífrasis resultativa epistulam scriptam habeo hasta convertirse en una forma verbal (HARRIS, 1982; ROMANI, 2006; OLIVEIRA, 2010). Entre los cambios, se consideran: (i) la construcción que antes ocurría solo con verbos télicos pasa a admitir verbos atélicos; (ii) el verbo habere poco a poco perdía el significado independiente de posesión y pasaba a funcionar como un verbo auxiliar; (iii) la coincidencia entre el sujeto del verbo flexionado y del participio se volvía obligatoria; y (iv) el participio perdía la función predicativa referente al objeto y, desde ahí, se perdía la marca de concordancia en número y género. Romani (2006, p. 243) aduce que la creación de formas verbales perifrásticas que expresan anterioridad ${ }^{14}$ es una innovación de las lenguas romances y cada variedad "evolucionó de manera distinta en lo que a la auxiliaridad [y la funcionalidad] se refiere" (ROMANI, 2006, p. 246).

De haberse convertido en una forma verbal con una función semántica definida, el pretérito perfecto compuesto no permanece mucho tiempo en el monosemanticismo. Los cambios morfosintácticos de la perífrasis a la forma verbal se estabilizan, pero los cambios semánticos siguen su trayecto: la forma se restringe a la expresión de estados presentes resultantes de acciones pasadas, sin describirlas por sí mismas, por más recientes que sean (etapa I/PPC de resultado); la forma ocurre solamente en situaciones bastante específicas, en contextos aspectualmente durativos o repetitivos (etapa II/PPC como operador aspectual); la forma pasa a indicar el valor prototípico del Present Perfect, una acción pasada con relevancia en el presente (etapa III/PPC de relevancia presente); y, finalmente, la forma pasa a desempeñar función pretérita y restringe su concurrente - el perfecto simple - a registros formales (etapa IV/PPC perfectivo), según Harris (1982, p. 49).

Sobre las etapas en que se encuentran las lenguas románicas - tema que recuperamos ligeramente por exceder los propósitos de la presente investigación -, recurrimos a Squartini y Bertinetto (2000) para quienes el valor puramente resultativo es una etapa superada por todas las variedades. En la etapa II, se encuentran el portugués y algunas variedades del español americano, como la mexicana, en la cual el perfecto designa situaciones durativas o iterativas (un operador aspectual). Fundamentados en estudios sobre el perfecto en Colombia, Puerto Rico, Islas Canarias y Buenos Aires, Squartini y Bertinetto (2000, p. 411-412) sostienen que en estos territorios el uso de esa forma verbal denota situaciones iterativas y durativas, igualmente a lo que sucede en el español mexicano.

${ }^{14}$ Anterioridad en relación a un punto de referencia que puede coincidir con el presente (he amado), con el pasado (había amado) o con el futuro (habré amado). 
Referente a la etapa III en la evolución del PPC - una de las más expresivas, puesto que es cuando la forma verbal pasa a recubrir situaciones puramente perfectivas (OLIVEIRA, 2010, p. 237) -, se reconoce que el español peninsular avanza en este proceso de transformación, demarcando la relevancia presente a través de esa forma verbal. En la etapa IV, en la cual el perfecto se extiende a cualquier contexto de pasado y el pretérito indefinido "se convierte en una forma verbal caduca, hasta llegar a desaparecer del todo en algún caso por la competencia de las formas compuestas" (CAMUS BERGARECHE, 2008, p. 96), se encuentran el italiano estándar, el francés, el rumano estándar y otras.

Según discuten diferentes autores (LOPE BLANCH, 1983; SPITZOVÁ; BAYEROVÁ, 1987; SQUARTINI; BERTINETTO, 2000; OLIVEIRA, 2010), el perfecto compuesto de algunas variedades hispanoamericanas expresa habitualmente situaciones durativas e iterativas (etapa II en el proceso de gramaticalización). Como ejemplificación, al describir la multifuncionalidad del PPC en noticias de repercusión internacional de periódicos hispánicos, Oliveira (2010) encuentra en los datos de:

México: uso predominante del PPC de Continuidad, función en la que se encuentran los valores durativo e iterativo, aunque aparezcan ocurrencias de la tercera etapa;

Argentina, Cuba, Bolivia y Chile: uso del PPC en dirección a la etapa III, ya que la proporción de datos de relevancia presente se amplía, aunque el de Continuidad (etapa II) sea aún superior;

Perú: uso en dirección similar, pero con un adelantamiento en la evolución, ya que es posible verificar el aumento de la frecuencia del PPC indicando relevancia presente, además de la presencia de un dato perfectivo, el cual representa la última etapa de evolución de esa forma verbal; $y$

España: frecuencia expresiva del PPC de relevancia presente (etapa III), indicando resultado persistente, experiencia y hecho reciente.

Cabe aclarar que en menor o mayor medida todas las variedades consideradas por Oliveira (2010) revelan el uso del PPC de relevancia presente - un dominio que abriga diferentes subdominios de sentidos graduales y de límites imprecisos, que, por su polivalencia, parece contribuir al aumento de la frecuencia y la aceleración en el proceso de cambio. Recuperamos de Squartini y Bertinetto (2000, p. 416) las funciones que recubre la relevancia presente: 
contextos inclusivos, que contemplan el momento de habla - He vivido aquí toda mi vida;

noticias recientes (hot news) - Ha llegado el rey;

contextos experienciales- $\boldsymbol{i}$ Has estado en Australia?;

resultados persistentes de una situación pasada - No, ha muerto; y

contextos con adverbios de tiempo que expresan pasado reciente - Hoy me he despertado a las cuatro de la madrugada.

Recobrando la baja frecuencia de la forma verbal gramaticalizada en el dominio de la relevancia presente en el corpus de Oliveira (2010) y reconociendo que en el dominio de la relevancia presente coexisten diferentes estratos (layers), indagamos cómo enuncian los periódicos hispanoamericanos situaciones pasadas vinculadas a la pandemia mundial cuyo resultado persiste o incide sobre el presente. Al tomar en cuenta los resultados de Oliveira (2010), se conjetura: (i) que las variedades aquí consideradas se comportarán distintamente, posiblemente con mayor frecuencia del PPC en el periódico peninsular en comparación con los periódicos hispanoamericanos; y (ii) que en estos últimos se identificarán más estratos en el dominio de la relevancia presente.

Direccionamos, así, el foco del lente del dominio funcional sobre la relevancia presente, la que recubre los subdominios de contexto inclusivo, de noticias recientes (en la cual contemplamos las de contextos adverbiales), de experiencia y de resultados persistentes de una situación pasada; aquí estrechamos el foco sobre el subdominio de la relevancia presente de resultado persistente (RPrp). En el análisis de los datos a continuación, buscamos: (i) demostrar la compleja tarea de recortar el objeto, es decir, el (sub)dominio funcional; (ii) presentar las construcciones que funcionan como estratos en el dominio de la relevancia presente; y (iii) señalar algunas tendencias en el corpus considerado.

\section{La relevancia presente en tiempo de pandemia: el fenómeno en las noticias}

Antes de pasar a la consideración de los datos, juzgamos conveniente mencionar algunos cuidados metodológicos llevados a cabo en esta investigación, los cuales empiezan a partir de una discusión informal entre los autores del presente texto. El dato que copiamos abajo no nos ha pasado inadvertido y, como investigadores del tiempo verbal, profesoras y traductores, hemos emprendido algunas discusiones y hemos retomado lecturas para la elaboración del corpus y el análisis.

Imagen 1 - Publicación en la red social Twitter 
Adolfo Sánchez Cuadrado

@SanchezC_Adolfo

"La pandemia de coronavirus mató a más de 30.000 personas en Europa" (AFP, 01-04-2020).

Un claro ejemplo del efecto del pretérito indefinido desde la perspectiva peninsular. Me ha emocionado el titular, parecía que esta pesadilla ya había terminado. Traduzir Tweet

7:41 AM · 1 de abr de $2020 \cdot$ Twitter Web App

Fuente: Sánchez Cuadrado (2020).

En este tuit, el usuario manifiesta la primera interpretación que le acciona el pretérito indefinido (al que nos referimos como pretérito perfecto simple). Para el hablante del español europeo, la forma mató expresa una situación pasada y acabada (perfectiva, en términos aspectuales) que "no" corresponde(ría) al escenario real de una pandemia cuyos efectos persisten en el presente de la enunciación. La reflexión epilingüística del usuario nos hace suponer que, para un hablante de la variedad peninsular, el PPS es una forma verbal marcada ${ }^{15}$ en el contexto de relevancia presente de resultado persistente, que le exige del hablante más tiempo de procesamiento de la información.

No obstante, es importante reconocer que, desde la perspectiva funcionalista, se considera la interpretación de forma marcada o no marcada a partir del contexto, cuya explicación debe partir de factores biológicos, cognitivos, socioculturales y comunicativos (GIVÓN, 1995). Para el presente estudio, hemos considerado una muestra bastante específica, que se constituye a partir del género textual noticia publicado virtualmente. En los pasos de Oliveira (2007; 2010), se mantiene el criterio de la coincidencia temporal del evento y de la publicación (en nuestro caso, la semana entre el 9 y el 17 marzo de 2020, momento en que se declara la pandemia de la COVID-19), así como de la coincidencia temática (los efectos de la pandemia) ${ }^{16}$. Desde nuestra lectura, consideramos que esa delimitación es bastante favorable al empleo de diferentes construcciones que expresan el resultado persistente de una situación pasada, construcciones que por el contexto considerado no exigen del lector mucho esfuerzo cognitivo en la interpretación de la función que las formas vehiculan. Para ejemplificar, observemos los datos a continuación que guardan cierta relación con el enunciado del tuit:

(1) La OMS declara pandemia por el nuevo coronavirus (Co/Declaración 
OMS/11 marz.).

(2) 15 casos, de los que solo ocho se han detectado en Wuhan y seis son importados de otros países. Además, han fallecido 11 personas (Es/China supera pico/12 marz.).

En (1) se encuentra el titular del periódico El Tiempo de Colombia, relacionado al contexto del anuncio realizado por la OMS el 11 de marzo de 2020. En este caso la forma que vehicula el significado que nos interesa es el tiempo presente. Esta elección se justifica por tratarse del registro de un hecho actual en el momento de la enunciación, que además es de interés público y trascendental, razones por las cuales el periodista debe buscar formas verbales que amparen el hecho como un evento reciente (VAN DIJK, 1990).

En (2) dato encontrado en el periódico El País de España, aparece la construcción del PPC expresando el significado de la relevancia presente al referirse (i) a la cantidad de casos detectados en Wuhan hasta el momento de la enunciación y (ii) al número de muertes registradas. El pretérito perfecto compuesto cumple una función bastante vinculada al género periodístico de la noticia, buscando mantener actuales los acontecimientos comunicados, principalmente cuando se trata de sucesos que pueden repetirse o que tienen potencial de llegar a tener un gran impacto a corto o mediano plazo.

Como evidencian los datos anteriores, diferentes estratos pueden configurarse en el subdominio de la relevancia presente con resultado persistente - el perfecto simple, el presente y el perfecto compuesto, como los que aquí se ilustran. Se señalaba anteriormente en este texto que el resultado persistente es uno de los subdominios de la relevancia presente, cuya semántica no es tan fácilmente interpretada, puesto que los límites entre las funciones ni siempre están al alcance del analista. Desde la perspectiva funcionalista, el continuo entre una función y otra es característica común en las formas polivalentes, puesto que la gramática, siempre emergente, prevé cambios graduales cuyos límites entre los distintos valores es siempre difícil determinar con precisión (HOPPER, 1998; GÖRSKI, 2017).

Para ejemplificar lo anterior, tomaremos algunos datos presentes en el corpus constituido:

(3) Wall Street tuvo suspendidas sus operaciones (Ar/Lunes negro/9 marz.).

(4) El incierto impacto económico del coronavirus continúa afectando a los mercados (Ar/Lunes negro/9 marz.). 
(5) Los mercados se están poniendo en el escenario más negativo (Es/Lunes negro/9 marz.).

(6) Shanghái, la capital económica china, ha comenzado a reabrir parcialmente algunos de sus lugares turísticos más emblemáticos (Es/China supera pico/12 marz.).

(7) Horas antes, las Bolsas europeas habían abierto en la mañana de este lunes (siguiendo la tendencia de las asiáticas) con una fuerte caída, la mayor para los mercados del Viejo Continente desde el 24 de junio de 2016, día posterior al referéndum del Brexit. Y terminaron con fuertes pérdidas ( $\mathrm{Ar} /$ Lunes negro/9 marz.).

(8) En lo que va de año las grandes bolsas europeas han perdido entre el $18 \mathrm{y}$ el 20\% (Ar/Lunes negro/9 marz.).

Desde nuestra lectura, a primera vista el conjunto de datos anterior parece guardar relación con el resultado o demarcar relevancia presente. Sin embargo, solamente los dos últimos, codificados en PPS y en PPC, hacen suponer la relevancia presente de resultado persistente. En (3) la perífrasis de aspecto perfectivo señala el resultado de una situación pasada sin guardar relación con el presente. Si retomamos los puntos establecidos por el análisis lógico de Reichenbach (1960), la construcción formada por el auxiliar tener (tuvo) y el participio flexionado (suspendidas) representan un único evento (E) que coincide con una referencia pasada, cuya fórmula sería E,R - S.

En (4) se encuentra una construcción perifrástica aspectual con un valor de duración reforzado por la semántica del verbo continuar acompañado de una forma en gerundio (afectando). Aunque comprenda el presente de la enunciación, la función es codificar la continuidad de la situación y no su resultado. Si la consideramos como un evento que se extiende del pasado hasta el presente, podríamos pensar en la fórmula EEE,R,S, la que explicita la imperfectividad de la situación.

En el dato en (5) la perífrasis estar + gerundio indica un cambio continuativo de estado, cuyos efectos (de una situación que empieza en el pasado) se sienten en el presente. Sin embargo, descartamos la interpretación de la subfunción que nos interesa justamente por la aspectualidad imperfectiva que guarda la perífrasis en discusión.

En una primera lectura vislumbramos en la construcción perifrástica ha comenzado a reabrir, dato en (6), el rasgo de relevancia presente de la situación expresada por el pre- 
dicado. Sin embargo, no nos parece tratarse de la aspectualidad de resultado persistente, sino de un tiempo interno que marca el inicio de un evento - la aspectualidad inceptiva, por lo tanto.

Ampliamos el contexto en (7) puesto que la interpretación aspectual de una situación exige una lectura más allá de los límites morfológicos. El verbo télico terminar indica que, de la caída de las Bolsas europeas en la mañana del lunes en que se publica la noticia, resultan las fuertes pérdidas, es decir, se trata del resultado persistente de una situación pasada, cuya fórmula reichenbachiana podría ser E - R,S. Es importante aclarar que la interpretación funcional del evento se da en el contexto, puesto que la fórmula default del PPS sería E, R - S, según nos muestra el cuadro 1 .

En (8) se alcanza la interpretación de resultado persistente de una situación pasada a partir de la telicidad del verbo perder acompañado de un complemento definido (el 18 y el 20\%) y de la conjugación en el pretérito perfecto compuesto, forma que a lo largo de su trayectoria de gramaticalización pasa a indicar la subfunción que aquí debatimos. Se trata de un evento pasado cuyos efectos/resultados se sienten en el presente; la fórmula temporal/aspectual es, por lo tanto, la de la subfunción que nos interesa en este estudio: $\mathrm{E}-\mathrm{R}, \mathrm{S}$.

Por otro lado, ciertos datos, por el conjunto de elementos del contexto (semántica del verbo, tipo de complementos y de modificadores adverbiales, por ejemplo), delimitan con más claridad la función que al analista le interesa analizar ( $\mathrm{y}$ cuantificar, cuando conveniente). Siguiendo nuestros propósitos, los datos de 9 a 16 ilustran lo que interpretamos como estratos que compiten en la función de RP de resultado persistente:

9. Desde que apareció el nuevo coronavirus en diciembre, se registraron en torno a 110.000 casos en 99 países y territorios (Ar/Lunes negro/9 marz.).

10. Los mercados entran en pánico por la guerra del petróleo y el coronavirus (Es/Lunes negro/9 marz.).

11. Coronavirus en España: el gobierno endurece las medidas de aislamiento y prohíbe los vuelos a Italia (Ar/Suspensión de vuelos/10 marz.).

12. "La epidemia contaminó la atmósfera de los mercados. Con las bolsas europeas y estadounidenses cayendo y el hundimiento del precio del petróleo, la epidemia es un catalizador" (Pe/Lunes negro/9 marz.).

13. El coronavirus, según expertos, contaminó 'atmósfera de los mercados' (Co/ 
Lunes negro/9 marz).

14. El Gobierno también ha suspendido los viajes del Imserso para mayores durante un mes para evitar contagios a grupos de riesgo (Es/Suspensión de vuelos/10 marz).

15. Gobierno prohibió los vuelos con Italia. Madrid suspendió clases por los próximos 15 días (Co/Suspensión de vuelos/10 marz.).

16. La Casa Blanca dio a conocer los resultados de la prueba (Pe/Trump negativo/14 marz.).

El dato en (9) aparece en un contexto que juzgamos de fácil interpretación de la función que nos interesa, puesto que los registros de casos es el resultado de una situación que se inicia en el pasado pero guarda relación con el presente, explícitamente codificada por el marcador temporal desde que.

Según el cuadro 1 el tiempo presente es por definición una forma absoluta, en que los tres puntos (E, Ry S) coinciden en la línea temporal. Sin embargo, en el género noticia el empleo del presente de indicativo es una estrategia para que se sustente la actualidad de los sucesos. Desde ahí, parece apropiado remplazar la fórmula default S, R, E a una fórmula más fiel a la función que los verbos en presente (entran, endurece y prohíbe) representan en los contextos reales recortados en (10) y (11): E - R,S.

Se observa en (12) y (13) que los periódicos de Perú y Colombia coinciden ${ }^{17}$ en la elección de la forma que codifica el resultado persistente de una situación pasada - los efectos de la pandemia sobre el mercado económico, más precisamente. El verbo contaminar es un tipo de predicado que denota el sentido resultativo; además, la temática central de la pandemia y la naturaleza del género textual intensifican la interpretación del perfecto simple en estos casos como estrato de la RPrp.

\footnotetext{
${ }^{17}$ Es importante recordar que en los medios de comunicación la sección que trasmite las noticias internacionales funciona a través de dos formas: (i) con corresponsales en las principales ciudades del mundo (seleccionadas estratégicamente); y (ii) replicando las noticias que llegan por agencias internacionales como EFE y AFP. Esto significa que muchas de las noticias encontradas en diversos diarios replican las noticias que a ellos llegan a través de estas agencias periodísticas. Este hecho lo pudimos verificar en los diarios de Argentina y Perú al publicar la noticia sobre la superación del pico de contagio en China. En las noticias podemos encontrar fragmentos que son prácticamente iguales, pero que adaptan algunos elementos del texto, entre ellos las formas verbales, al uso del país, tal y como lo podemos observar en los siguientes datos: "El pico de transmisiones del nuevo coronavirus en China llegó a su fin, anunció este jueves la Comisión Nacional de Salud del país asiático durante una rueda de prensa en Beijing" (Ar/China supera pico/12 marz.) y "El pico de transmisiones de COVID-19 en China ha llegado a su fin, anunció este jueves un portavoz de la Comisión Nacional de Salud del país asiático durante una rueda de prensa en Beijing" (Pe/China supera pico/12 marz.).
} 
El contexto ilustrado en (14) y (15) es bastante frecuente en el tipo de corpus que hemos considerado. Desde que ha sido declarada la pandemia, diversos periódicos vehiculan noticias sobre las diferentes medidas y decisiones de los gobiernos, las que per se indican los resultados presentes de un hecho pasado. Suspender y prohibir, verbos conjugados en el pretérito perfecto simple en nuestros recortes, son situaciones pasadas que guardan relación con el presente o, mejor dicho, que siguen impactando el momento de la enunciación.

En (16) se destaca lo que tratamos como locuciones verbales, en este caso construida a partir del verbo dar + preposición + infinitivo. En una línea temporal imaginaria, dio a conocer (es conocido, por lo tanto) se refiere a un evento que se localiza a la izquierda del momento del habla, el cual sirve como punto de referencia en la codificación de la relevancia presente.

El conjunto de datos anterior sostiene la variación en el subdominio de la RP de resultado persistente, una función característica del género noticia especialmente cuando está en referencia a un hecho de impacto expresivo sobre el presente, como es el caso de la pandemia. En el recorte que aquí se ha considerado, es decir, en la muestra de las cinco noticias publicadas por periódicos de Argentina, Colombia, España y Perú, la frecuencia de uso de los diferentes estratos identificados es la que se presenta en la tabla 1 a continuación.

Tabla 1 -Estratos contemplados en el subdominio de la RPrp

\begin{tabular}{|c|c|c|c|c|}
\hline \multirow[t]{2}{*}{ Estratos } & \multicolumn{4}{|c|}{ Países } \\
\hline & Argentina & Colombia & España & Perú \\
\hline PPS & $\begin{array}{c}9 \\
(47,3 \%) \\
\end{array}$ & $\begin{array}{c}6 \\
(50 \%) \\
\end{array}$ & 0 & $\begin{array}{c}3 \\
(\mathbf{1 5 \%}) \\
\end{array}$ \\
\hline $\mathrm{PPC}^{18}$ & $\begin{array}{c}4 \\
(21,1 \%) \\
\end{array}$ & 0 & $\begin{array}{c}21 \\
(\mathbf{8 7}, 5 \%) \\
\end{array}$ & $\begin{array}{c}15 \\
(75 \%) \\
\end{array}$ \\
\hline Presente & $\begin{array}{c}3 \\
(15,8 \%) \\
\end{array}$ & $\begin{array}{c}5 \\
(41,7 \%) \\
\end{array}$ & $\begin{array}{c}1 \\
(4,2 \%) \\
\end{array}$ & $\begin{array}{c}1 \\
(5 \%) \\
\end{array}$ \\
\hline $\begin{array}{c}\text { Locuciones } \\
\text { verbales }\end{array}$ & $\begin{array}{c}3 \\
(15,8 \%) \\
\end{array}$ & $\begin{array}{c}1 \\
(8,3 \%)\end{array}$ & $\begin{array}{c}2 \\
(8,3 \%) \\
\end{array}$ & $\begin{array}{c}1 \\
(5 \%) \\
\end{array}$ \\
\hline
\end{tabular}

${ }^{18}$ Cabe aclarar que en este cuantitativo se consideran, obviamente, solamente los datos de RPrp. En el corpus esa forma verbal se presenta con otros valores, como: experiencial-“Ya hemos pasado lo peor" (Es/ China supera pico/12 marz.) y operador aspectual - "He estado en contacto diariamente con el Centro de Control de Enfermedades" (Pe/China supera pico/12 marz.). La multifuncionalidad del PPC, sin embargo, no es un tema al que aquí se pone atención. 


\begin{tabular}{c|c|c|c|c}
\hline Total & $\begin{array}{c}19 \\
(\mathbf{1 0 0 \%})\end{array}$ & $\begin{array}{c}12^{19} \\
(\mathbf{1 0 0 \%})\end{array}$ & $\begin{array}{c}24 \\
(\mathbf{1 0 0 \%})\end{array}$ & $\begin{array}{c}20 \\
(\mathbf{1 0 0 \%})\end{array}$ \\
\hline
\end{tabular}

Fuente: Elaboración propia.

El análisis preliminar de esta etapa de constitución del corpus indica mayor porcentaje del pretérito perfecto simple en el subdominio de la relevancia presente de resultado persistente en Colombia (50\%) y en Argentina (47,3\%); en España y Perú ocupa esta función mayoritariamente el pretérito perfecto compuesto ( $87,5 \%$ y $75 \%$, respectivamente).

Específicamente sobre el resultado de Perú, es interesante destacar que entre las cuatro muestras se trata de la más reducida en términos de cantidad de palabras (1326) - con menos de la mitad si se compara con la de España/3583 y la de Argentina/3226, teniendo en cuenta el conjunto de las cuatro noticias coincidentes en los contextos geográficos considerados. Ante esa realidad el número absoluto de frecuencia del PPC en la muestra peruana merece aquí nuestro relieve. Explicitando mejor, lo que aquí se busca argumentar es que, si comparamos los estratos verificados en el diario hispanoamericano de Argentina, los 19 datos se distribuyen en todos ellos (PPS/9, PPC/4, Presente/3 y Locuciones verbales/3), con mayor frecuencia de uso del perfecto simple, como se puede observar. En Perú, la RPrp está codificada por las mismas construcciones, pero con una frecuencia expresivamente superior del perfecto compuesto (PPS/3, PPC/15, Presente/ 1 y Locuciones verbales/1).

Es posible interpretar este resultado como un argumento a favor del avance en el proceso de gramaticalización del PPC tanto en Perú como en España, contextos en que la forma verbal alcanza la etapa III en su proceso de cambio, de acuerdo con la discusión de Harris (1982) y Oliveira (2010) presentadas en la sección 2.3. También es importante recordar que Oliveira (2010) encuentra en la escritura periodística de Madrid y Lima mayor frecuencia del PPC de relevancia presente (etapa III), comparada a la escritura de otras cinco capitales hispánicas en que el PPC continuativo (etapa II) es más frecuente.

En la tabla 1 interesa además destacar el número equilibrado de ocurrencias en presente de indicativo y en locuciones verbales en Argentina (15,8\%) y el uso productivo del presente en Colombia (41,7\%); en esta variedad, la frecuencia de locuciones verbales es del 8,3\%, solamente un dato. La frecuencia de estas construcciones en España y Perú es

\footnotetext{
19 Es importante aclarar que la discrepancia en el total de frecuencia de los datos interpretados como RPrp no sucede de la diferencia funcional de las construcciones, sino de la extensión de las noticias. Si tan solo tomamos en cuenta las cuatro noticias que coinciden en los cuatro diarios considerados, la muestra de El País de España cuenta con una extensión de 3583 palabras; mientras que, en el caso de El Tiempo de Colombia, el número se reduce a 2447. Recordamos que la noticia sobre la superación del pico de contagio de COVID-19 en China no fue publicada por este último diario.
} 
poco expresiva. Desde ahí, se infiere que al proceso más lento de gramaticalización del PPC se relaciona a la existencia de diferentes recursos para expresar la RP de resultado persistente - una vez restringido el uso del PPC en esta función, otras formas son accionadas por el hablante.

\section{Consideraciones finales}

La lingüística popular practicada en las redes sociales ha despertado en los lingüistas y los interesados en fenómenos del lenguaje importantes formulaciones sobre los usos emergentes, la variación y los valores que oscilan según el contexto geográfico o sociocultural. En un momento en que el mundo comparte el interés por la misma información, las noticias sobre un mismo hecho parecen acelerarse y de ahí resultan interesantes datos y reflexiones sobre la lengua, como la ilusión manifiesta en el tuit presentado en la imagen 1 , sección 3 .

En un contexto de pandemia, el efecto que le provoca a un hablante de la variedad peninsular el pretérito indefinido - que en este texto se denomina pretérito perfecto simple (PPS) - es el punto inicial de la investigación que aquí recortamos, que parte del interés en averiguar cómo enuncian los periódicos hispanoamericanos situaciones pasadas vinculadas a la pandemia mundial cuyo resultado persiste o incide sobre el presente. Como secuencia a caminos recorridos anteriormente (OLIVEIRA, 2007; 2009; 2010), se elabora un corpus que juzgamos oportuno para el estudio de la relevancia presente de resultado persistente, un subdominio situado en el macrodominio de la anterioridad. El corpus se constituye de noticias de repercusión mundial, relacionadas al tema de la pandemia de la COVID-19, publicadas en diferentes periódicos hispánicos. Con base en el cuestionamiento recuperado unas líneas arriba, conjeturamos: (i) que las variedades consideradas se comportarían de manera distinta, posiblemente con mayor frecuencia del PPC en el periódico peninsular en comparación con los periódicos hispanoamericanos; y (ii) que en estos últimos se identificarían más estratos en el dominio de la relevancia presente. En el análisis preliminar, se confirma la primera hipótesis y se confirma parcialmente la segunda. Las noticias de Argentina y Colombia se equiparan en lo que concierne a la preferencia por el perfecto simple en la codificación de la relevancia presente de resultado persistente. El perfecto compuesto es la forma predominante en España, pero también en Perú, en este subdominio. En las variedades en que el PPC avanza más lentamente en el proceso de gramaticalización (OLIVEIRA, 2010), como la de Argentina, se constatan diferentes formas que compiten por el mismo trabajo - el de expresar la RPrp (formas del pretérito perfecto simple, del pretérito perfecto compuesto, del presente y locuciones 
verbales). Colombia es el país con mayor frecuencia de uso del presente de indicativo en el subdominio que nos interesa.

Además de discutir estos resultados preliminares, buscamos ilustrar la compleja tarea de recortar el objeto, es decir, el (sub)dominio funcional, y también la tarea de identificar los estratos que compiten en esta función.

Finalizando, hemos dado un paso cauteloso a través del recorte de un corpus que, a pesar de reducido, nos ha permitido alcanzar los propósitos delineados. Esperamos que a partir de este estudio menos ambicioso diferentes investigaciones de mayor envergadura puedan corroborar o discrepar los resultados aquí debatidos.

\section{Referencias}

ALARCOS LLORACH, Emilio. Gramática funcional del español. Madrid: Gredos, 1984. BELLO, Andrés. Análisis ideológico de los tiempos de la conjugación castellana. Caracas: Ministerio de la Educación, 1972 [1841].

BELLO, Andrés. Análisis ideológico de los tiempos de la conjugación castellana. In: Obra Literaria. Caracas: Ayacucho, 1979 [1810], p. 415-459.

BYBEE, Joan. From usage to grammar: the mind's response to repetition. Language, no 82, 2006, p. 711-733.

BYBEE, Joan.Língua, uso e cognição.Traducción de Maria Angélica Furtado da Cunha; revisión técnica de Sebastião Carlos Leite Gonçalves. São Paulo: Cortez, 2016.

CÂMARA JÚNIOR, Joaquim Mattoso. Estrutura da língua portuguesa. Petrópolis: Editorial Vozes, 1970.

CAMUS BERGARECHE, Bruno. El perfecto compuesto (y otros tiempos compuestos) en las lenguas románicas: formas y valores. In: CARRASCO GUTIÉRREZ (Ed.). Tiempos compuestos y formas verbales complejas. Madrid: Iberoamericana Editorial Vervuert, 2008, p. 65-99.

CASTILHO, Ataliba Teixeira de. Introdução ao estudo do aspecto verbal na língua portuguesa. Marília: Facultad de Filosofía, Ciencias y Letras, 2003.

CASTILHO, Ataliba Teixeira de. Nova gramática do português brasileiro. São Paulo: Contexto, 2010.

COMRIE, Bernard. Aspect. Cambridge: Cambridge University Press, 1981.

COMRIE, Bernard. Tense. Cambridge: Cambridge University Press, 1985.

COSERIU, Eugenio. Norma y habla. Revista de la Facultad de Humanidades y Ciencias. Año VI, n. 9, Montevideo, 1952.

COSERIU, Eugenio. Sincronía, diacronía e historia. Madrid: Gredos, 1973.

COSERIU, Eugenio. El hombre y su lenguaje. Madrid: Gredos, 1977. 
COSERIU, Eugenio. Sentido y tareas de la dialectología. Cuadernos de Língüística, n. 8. Ciudad de México: Instituto de Investigaciones Filológicas, Centro de Lingüística Hispánica, 1982.

CUNHA, Maria Angélica Furtado da; COSTA, Marcos A.; CEZÁRIO, Maria M. Pressupostos teóricos fundamentais. In: CUNHA, M. A. F. da; OLIVEIRA, M. R. de; MARTELOTTA, M. E. (Org.). Linguística funcional: teoria e prática. Río de Janeiro: DP\&A, 2003, p. 29-55.

FOSSILE, Dieysa Kanyela. Valores aspectuais do português brasileiro e do alemão: uma proposta de síntese. In: MOURA, H., BORGES, M., SANTANA, A. P. (Org.) Cognição, Léxico e Gramática. Coleção Linguística. V.1. Florianópolis: Insular, 2012, p. 47-93.

GARCÍA FERNÁNDEZ, Luis. La gramática de los complementos temporales. Madrid: Visor Libros, 2000.

GESSER, Alison Felipe. Funcionalidad de formas verbales de pasado: análisis lingüístico de una película brasileña traducida al español. Tesis (Licenciatura). Centro de ComunicaciónyExpresión. Departamento de Lengua y Literatura Extranjeras. Florianópolis: Universidad Federal de Santa Catarina, 2015.

GESSER, Alison Felipe. Funcionalidades do pretérito perfeito espanhol em traduções para dublagem: análise de corpus fílmico. 2018. 326 p. Tesis (Maestría) - Universidad Federal de Santa Catarina, Centro de Comunicación y Expresión, Programa de Posgrado en Lingüística, Florianópolis, 2018. Disponible en: http://www.bu.ufsc.br/teses/ PLLG0725-D.pdf. Consultado: 7 agosto 2020.

GIBBON, Adriana de Oliveira. Trajetória de gramaticalização da perífrase IR (presente) + infinitivo no domínio funcional do futuro: análise sincrônica e diacrônica em amostras de fala e escrita gaúchas. 2014. 365 p. Tesis (Doctorado) - Universidad Federal de Santa Catarina, Centro de Comunicación y Expresión, Programa de Posgrado en Lingüística, Florianópolis, 2014.

GIVÓN, Talmy. Functionalism and grammar. Amsterdam/Philadelphia: J. Benjamins, 1995.

GIVÓN, Talmy. Tense, aspect and modality I: functional organization. In: Syntax: an introduction. v. 1. Amsterdam/Philadelphia: J. Benjamins, 2001a, p. 285-335.

GIVÓN, Talmy. The functional approach to language and the typological approach to grammar. In:Syntax: an introduction. Amsterdam/Philadelphia: J. Benjamins, 2001b, p. $1-42$.

GIVÓN, Talmy. Bio-linguistics. Philadelphia: John Benjamins, 2002.

GODOY ROA, María Alejandra. Estudo do tempo e do aspecto no uso de construções fraseológicas do espanhol: um olhar para a frequência com base em corpora. 2017. 198 p. Tesis (Maestría) - Universidad Federal de Santa Catarina, Centro de Comunicación y Expresión, Programa de Posgrado en Lingüística, Florianópolis, 2017. Disponible en: http://www.bu.ufsc.br/teses/PLLG0680-D.pdf. Consultado: 7 agosto 2020. 
GÖRSKI, Edair Maria. A questão do continuum na interface variação/gramaticalização. In: MATZENAUER, C. L. B.; MIRANDA, A. R.; AMARAL, L. I. C. (Org.). Estudos da linguagem - VII Círculo de Estudos Linguísticos do Sul, 2006. Pelotas: EDUCAT, 2008, p. 145-172.

GÖRSKI, Edair Maria. Emergência de dar pra/de no domínio funcional da auxiliarização modal deôntica. Fórum Linguístico, v.17, n.1, p. 4342-4356, enero/marzo2020.

GORSKI, Edair Maria; et al. Fenômenos discursivos: resultados de análises variacionistas como indícios de gramaticalização. In: ROCARATI, C.; ABRAÇADO, J. (Org.). Português brasileiro: contato linguístico, heterogeneidade e história I. Río de Janeiro: 7 Letras, 2003, p. 106-122.

GÖRSKI, Edair Maria; TAVARES, Maria Alice. Reflexões teórico-metodológicas a respeito de uma interface sociofuncionalista. Revista do GELNE, Caicó, v. 15, n. 1/2, p. 75-97, 2013.

GÖRSKI, Edair Maria; TAVARES, Maria Alice. O objeto de estudo na interface variaçãogramaticalização. In: BAGNO, M.; CASSEB-GALVÃO, V.; REZENDE, T. F. (Org.) Dinâmicas funcionais da mudança linguística. São Paulo: Parábola, 2017, p.35-63.

GÖRSKI, Edair Maria; OLIVEIRA, Leandra Cristina de; PIMPÃO, Tatiana Schwochow. Do discurso para a gramática, da gramática para o discurso: uma entrevista com Sebastião Josué Votre. Working Papers em Linguística, 21(1): 8-16, Florianópolis, ene./ jul. 2020. Disponible en: https://periodicos.ufsc.br/index.php/workingpapers/article/ view/1984-8420.2020v21n1p8/43851. Consultado: 7 agosto 2020.

HARRIS, Martin. The "past simple" and "present perfect" in Romance. In: VINCENT, N.; HARRIS, M. (Ed.). Studies in the Romance Verb. Londres: Croom Helm, 1982, p. 42-70.

HOPPER, Paul. On some principlesof grammaticization. In: TRAUGOTT, E.; HEINE, B. (Ed.). Approaches to Grammaticalization. Ámsterdam: John Benjamins, 1991, p. 17-35.

HOPPER, Paul. The Paradigm at the End of the Universe. In: RAMAT, A. G.; HOPPER, P. J. (Org.) The limits of gramaticalization. Ámsterdam: John Benjamins, 1998, p. 147-158.

LABOV, William. Where does the linguistic variable stop? A response to Beatriz Lavandera. Working Papers in Sociolinguistics, 44. Austin: Southwest Educational Development Laboratory, 1978.

LABOV, William. Padrõe ssociolinguísticos. Traducción de Marcos Bagno, Maria Marta Pereira Scherrey Caroline Rodrigues Cardoso. São Paulo: Parábola, 2008 [1972].

LAPESA, Rafael. Historia de la lengua española. IX edición corregida y aumentada. Biblioteca Románica Hispánica. III. Manuales, 45. Madrid: Gredos, 1981.

LAVANDERA, Beatriz R. Where does the sociolinguistic variable stop? In: Language in Society, Great Britain, 1978, p. 171-182.

LOPE BLANCH, Juan Miguel. Estudios sobre el español de México. Ciudad de México: 
Universidad Nacional Autónoma de México, 1983, p. 131-143.

MILROY, Lesley; GORDON, Matthew. Beyond phonology: analyzing and interpreting higher level variation. In: MILROY, L.; GORDON, M. Sociolinguistics: method and interpretation. Oxford: Blackwell, 2003, p. 169-197.

OLIVEIRA, Leandra Cristina de. As duas formas do pretérito perfeito em espanhol: análise de corpus. Florianópolis, 2007. 130 f. Tesis (Maestría) - Universidad Federal de Santa Catarina, Centro de Comunicación y Expresión, Programa de Posgradoen Lingüística. Disponible en: http://tede.ufsc.br/teses/PLLG0379.pdf. Consultado: 7 agosto 2020.

OLIVEIRA, Leandra Cristina de. A atuação das modalidades epistêmicas "pressuposição" e "irrealis" no uso dos pretéritos perfeito simples eperfeito composto em espanhol. WorkingPapers em Linguística, v. 9, n. 2. Florianópolis: UFSC, 2008, p. 11-21.

OLIVEIRA, Leandra Cristina de. A noção de regra variável na morfossintaxe: um estudo sobre as formas verbais espanholas "dejó" e "ha dejado". Working Papers em Linguística, v. 10, n. 2. Florianópolis: UFSC, 2009, p. 21-33.

OLIVEIRA, Leandra Cristina de. Estágio da gramaticalização do pretérito perfeito composto no espanhol escrito de sete capitais hispano-falantes. 270 p. Tesis (Doctorado) - Universidad Federal de Santa Catarina, Centro de Comunicación y Expresión, Programa de Posgrado en Lingüística, Florianópolis, 2010. Disponible en: http://www.tede.ufsc.br/teses/ PLLG0465-T.pdf. Consultado: 7 agosto 2020.

OLIVEIRA, Leandra Cristina de. "He vivido" y "tenho vivido": funciones y trayectorias de cambio del perfecto compuesto español y portugués. Anuario Brasileño de Estudios Hispánicos, 2011, p. 60-80. Disponible en: https://sede.educacion.gob.es/publiventa/ detalle.action? cod=15659. Consultado: 7 agosto 2020 .

OLIVEIRA, Leandra Cristina de. A variação diatópica no sistema verbal espanhol. Working Papers em Linguística, v. 14, 2013, p. 121-132.

OLIVEIRA, Leandra Cristina de. O multifucional pretérito perfeito composto espanhol em materiais didáticos. Calidoscópio, v. 12, 2014, p. 83-93. Disponible en: http://revistas. unisinos.br/index.php/calidoscopio/article/view/cld.2014.121.09/4076.Consultado: 7 agosto 2020.

OLIVEIRA, Leandra Cristina de; GESSER, Alison Felipe. Funcionalidade de formas verbais de passado: uma interface entre linguística e tradução. In: XVII Congresso Internacional da ALFAL. Estudos linguísticos e filológicos. João Pessoa: Ideia, 2014. p. 27332749.

OLIVEIRA, Leandra Cristina de; GESSER, Alison Felipe. La expresión temporal de pasado en el material de audio de una película brasileña traducida en México. Verbum et Lingua, v. 5, 2015, p. 39-56. Disponible: http://verbumetlingua.cucsh.udg.mx/temas / portuguese. Consultado: 7 agosto 2020.

OLIVEIRA, Leandra Cristina de; GODOY ROA, María Alejandra. De la fraseología a 
una perspectiva cognitivista centrada en el uso: un debate sobre variabilidad y fijación. Revista de Estudos da Linguagem, v. 28, 2020, p. 331-358.

POPLACK, Shana. Grammaticalizationandlinguisticvariation. In: NARROG, H.; HEINE, B. (Ed.). The Oxford handbook of grammaticalization. Oxford: Oxford University Press, 2011, p. 209-224.

REICHENBACH, Hans. Elements of Symbolic Logic. New York: Macmillan Company, 1960.

ROMANI, Patricia. Tiempos de formación romance I. Los tiempos compuestos. In: COMPANY COMPANY, C. Sintaxis histórica de la lengua española. Primera parte: frase verbal, volumen I. Ciudad de México: Fondo de Cultura Económica/Universidad Nacional Autónoma de México: FCE, UNAM, 2006, p. 243-346.

SAID ALI, Manuel. Gramática histórica da língua portuguesa. 3a ed. Río de Janeiro: Melhoramentos, 1964.

SÁNCHEZ CUADRADO, Adolfo. "La pandemia de coronavirus mató a más de...” 1 de abril de 2020. Twitter: @SanchezC_Adolfo. Disponible en: https://twitter.com/ SanchezC_Adolfo/status/1245300260659920908. Consultado: 27 julio 2020.

SPITZOVÁ, Eva; BAYEROVÁ, Marcela. Posición del perfecto compuesto en el sistema temporal del verbo en el español de México. Études Romanes de Brno, 1987, XVIII(9), p. 37-50.

SQUARTINI, Mario; BERTINETTO, Pier Marco. The simple and compound past in Romance Languages. In: DAHL, Ö. Tense and aspect in the languages of Europe. Berlín: Mouton de Gruyter, 2000, p. 385-402.

TAGLIAMONTE, Sali. Analysing Sociolinguistic Variation.Cambridge: Cambridge University Press, 2006.

VAN DIJK, Teun Adrianus. La noticia como discurso. Ediciones Paidós Ibérica: Barcelona, 1990.

WEINREICH, Uriel; LABOV, William; HERZOG, Marvin. Fundamentos empíricos para uma teoria da mudança linguística. Traducción de Marcos Bagno. São Paulo: Parábola, 2006 [1968].

Data de submissão: 08/08/2020

Data de aceite: 07/09/2020

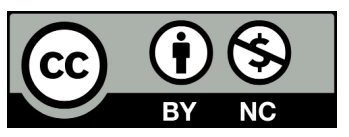

